\section{AB0143 PERIODONTITIS AND SALIVA ANTIBODIES TO CITRULLINATED PEPTIDES IN RHEUMATOID ARTHRITIS}

Anna Svärd ${ }^{1}$, Stefan Renvert ${ }^{2}$, Johan Berglund ${ }^{3}$, Maria Söderlin $4 .{ }^{1}$ Center for clinical research Dalarna, Uppsala University, Falun, Sweden; ${ }^{2}$ University of Kristianstad, Krisitianstad, Sweden; ${ }^{3}$ Blekinge Institute of Technology, Karlskrona, Sweden; ${ }^{4}$ Department of Clinical Sciences, Section of Rheumatology, Lund University, Lund, Sweden

Background: Mucosal immunity, involving antibodies against citrullinated peptides (ACPA), is a prevailing hypothesis concerning the pathogenesis of rheumatoid arthritis (RA). The oral mucosa is a possible site that is involved. Several epidemiological studies have found an association between RA and periodontitis, and periodontal inflammation has been suggested as a possible pathogenic factor.

In established RA, periodontitis has been associated with ACPA positivity (1) although a recent large study (2) did not find any association between periodontitis and IgG ACPA. Previous studies only evaluate ACPA in serum, and as local mucosal immune responses are likely involved in periodontitis, saliva antibodies are of interest to investigate. Saliva IgA ACPA has in a pilot study of RA patients been associated with lower disease activity and less erosions(3), but has not previously been evaluated in relation to periodontitis.

Objectives: To evaluate if saliva or serum ACPA is associated to periodontitis, in patients with RA.

Methods: In this population-based cohort of patients with RA ( $n=132)$, we included all patients with RA older than 61 years, living in Karlskrona in southern Sweden, between October 21, 2013 and January 7, 2015.

The patients underwent a clinical examination by a rheumatologist, a dental clinical examination by a dental nurse and a panorama radiograph of the jaws and teeth. Periodontitis was defined as a distance from the cement-enamel junction (CEJ) to the bone level $\geq 5 \mathrm{~mm}$, as defined by the radiographic assessment, at $\geq$ $30 \%$ of interproximal sites.

We analysed antibodies against second generation cyclic citrullinated peptides (anti-CCP) in enzyme immunoassays in serum and saliva. Saliva samples were analysed in parallel for anti-CCP and anti-CAP, the arginine containing control peptide. Serum ACPA positivity was defined as the $99^{\text {th }}$ percentile of healthy controls. In saliva, a positive test was defined as a difference in optical density (OD) for IgA anti-CCP and IgA anti-CAP (delta OD) $>0$.

Results: Saliva IgA ACPA was found in $11 \%$ of RA patients with periodontitis and in $24 \%$ of RA patients with no periodontitis $(p=0.052)$. There was no difference between the groups concerning $\lg G$ or IgA ACPA in serum.

Table 1. Demographic and laboratory characteristics of the study participants

\begin{tabular}{|c|c|c|c|}
\hline & $\begin{array}{l}\text { Patients with } \mathrm{RA} \text { and } \\
\text { periodontitis } \\
\mathrm{N}=80\end{array}$ & $\begin{array}{c}\text { Patients with RA no } \\
\text { periodontitis } \\
\mathrm{N}=52\end{array}$ & $\begin{array}{c}\mathrm{P} \\
\text { value* }\end{array}$ \\
\hline & Mean or percent & Mean or percent & \\
\hline Age at inclusion, years & 71.4 & 69.0 & 0.034 \\
\hline Females\% & $71 \%$ & $69 \%$ & 0.847 \\
\hline Disease duration, years & 12.1 & 12.3 & 0.930 \\
\hline DAS28 ESR & 3.01 & 2.84 & 0.403 \\
\hline DAS28 CRP & 2.81 & 2.80 & 0.936 \\
\hline $\begin{array}{l}\text { Erosions in hands or feet } \\
\%\end{array}$ & $59 \%$ & $53 \%$ & 0.584 \\
\hline Biologics currently\% & $21 \%$ & $23 \%$ & 0.806 \\
\hline Biologics ever\% & $36 \%$ & $44 \%$ & 0.577 \\
\hline $\begin{array}{l}\text { Smoker (ever vs } \\
\text { never)\% }\end{array}$ & $64 \%$ & $60 \%$ & 0.714 \\
\hline $\begin{array}{l}\text { Serum IgG ACPA } \\
\text { positive, } \%\end{array}$ & $66 \%$ & $69 \%$ & 0.849 \\
\hline $\begin{array}{l}\text { Serum IgA ACPA } \\
\text { positive, } \%\end{array}$ & $35 \%$ & $43 \%$ & 0.461 \\
\hline $\begin{array}{l}\text { Saliva IgA ACPA } \\
\text { positive, } \%\end{array}$ & $24 \%$ & $11 \%$ & 0.052 \\
\hline
\end{tabular}

*Student's T-test was used for continuous variables and Fischer's exact test for categorical variables.

A logistic regression analysis adjusting for gender, age and smoking showed an Odds Ratio of 0.299 (95\% Cl=0.096-0.929, $\mathrm{p}=0.037)$ for RA patients with periodontitis to be positive for saliva IgA ACPA, compared to RA patients with no periodontitis.

Conclusion: A weak, negative, correlation was observed between periodontitis and saliva IgA ACPA, when adjusting for age, sex and smoking. No correlation was observed between periodontitis and $\lg A$ or $\lg$ G ACPA in serum. In this cohort of patients with established RA, our findings do not support the hypothesis that periodontitis leads to increased formation of IgA ACPA in saliva or serum.

\section{REFERENCES}

[1],Dissick

A, et al. J Periodontol. 2010;81(2):223-30.
[2] Eriksson K, et al. PloS one. 2016;11(5):e0155956.

[3] Svärd A, et al. Immunobiology. 2013;218(2):232-7.

Disclosure of Interests: None declared

DOI: 10.1136/annrheumdis-2019-eular.1209

\section{AB0144 EFFECTS OF AB501 (CERTOLIZUMAB MICE EQUIVALENT) IN ARTHRITIS INDUCED BONE LOSS}

Bruno Vidal ${ }^{1}$, Mikko A. Finnilä ${ }^{2}$, Inês Lopes ${ }^{1}$, Rita Cascão ${ }^{1}$, Joao

Eurico Fonseca ${ }^{1,3} .{ }^{1}$ Unidade de Investigação em Reumatologia, Instituto de Medicina Molecular, Faculdade de Medicina, Universidade de Lisboa, Centro Académico de Medicina de Lisboa, Lisboa, Portugal; ${ }^{2}$ Research Unit of Medical Imaging, Physics and Technology, Faculty of Medicine, University of Oulu, Oulu, Finland; ${ }^{3}$ Serviço de Reumatologia e Doenças Ósseas Metabólicas, Hospital de Santa Maria, CHLN, Centro Académico de Medicina de Lisboa, Lisboa, Portugal

Background: Rheumatoid arthritis $(R A)$ is a chronic immune-mediated inflammatory disease, which causes local and systemic bone damage.

Objectives: The main goal of this work was to analyze, how treatment interven tion with Ab501 (certolizumab mice equivalent) prevents the disturbances on bone structure and mechanics induced by arthritis.

Methods: Thirty one DBA/1 collagen-induced arthritis $(\mathrm{CIA})$ mice were randomly housed in experimental groups, as follows: arthritic untreated $(\mathrm{N}=10)$, preventive intervention with ab501 2 days before arthritis induction $(\mathrm{N}=10)$ and treatment intervention upon arthritis onset with ab501 $(\mathrm{N}=11)$. A non-induced group $(\mathrm{N}=5)$ was used as a control. Mice were monitored during 70 days after disease induction for the inflammatory score, ankle perimeter and body weight. Non-induced mice were used as controls. After 70 days of disease progression mice were sacrificed and bone samples were collected for histology, micro-computed tomography $(\mu \mathrm{CT})$ and 3-point bending analysis. In addition, blood samples were also collected for bone turnover markers quantification. Statistical differences were deter mined with Mann-Whitney tests using GraphPad Prism (GraphPad, California, USA). Data were expressed as median with interquartile range. Differences were considered statistically significant for $\mathrm{p}<0.05$

Results: Results showed that Ab501 administration was able to control and abro gate disease development both in preventive and early therapeutic intervention $\mu \mathrm{CT}$ results revealed that ab501 was able to preserve bone structure when delivered before arthritis induction.

Conclusion: Ab501 preventive administration was able to control inflammation and prevent the degradative effects of arthritis on trabecular bone structure.

Acknowledgement: This work was supported by UCB in the context of an Inves tigator Initiated Study where UCB provided financial and product support.

Disclosure of Interests: Bruno Vidal Grant/research support from: Aspire Pfizer 2013, Mikko A. Finnilä: None declared, Inês Lopes: None declared, Rita Cascão: None declared, Joao Eurico Fonseca: None declared

DOI: 10.1136/annrheumdis-2019-eular.7025

\section{AB0145 THE INHIBITION OF JAK PATHWAY WAS ASSOCIATED WITH REDUCTION OF AUTOPHAGY IN SYNOVIOCYTES FROM RHEUMATOID ARTHRITIS PATIENTS}

Marta Vomero ${ }^{1}$, Mattia Caliste ${ }^{1}$, Cristiana Barbati ${ }^{1}$, Tania Colasanti ${ }^{1}$,

Francesca Spinelli ${ }^{1}$, Fulvia Ceccarelli ${ }^{1}$, Carlo Perricone ${ }^{1}$, Annacarla Finucci ${ }^{1}$,

Mariangela Speziali ${ }^{1}$, Alessandra Ida Celia ${ }^{1}$, Michele Bombardieri $^{2}$, Fabrizio Conti ${ }^{1}$, Guido Valesini ${ }^{1}$, Cristiano Alessandri'. ' Sapienza University of Rome, Internal Medicine and Medical Specialties, Rome, Italy, ${ }^{2}$ Queen Mary University of London, London, United Kingdom

Background: The pathway of Janus tyrosine kinases (JAKs) has a central role in the pathogenesis of rheumatoid arthritis (RA) by regulating multiple immune functions and cytokine production. The orally available JAK inhibitor CP-690,550, named tofacitinib, is able to inhibit Jak1, Jak2 and Jak3 and it showed a great clinical efficacy in RA patients not responding to methotrexate or TNF-inhibitors (1) Autophagy, a highly conserved mechanism involved in the degradation of intracellular components, was found to be dysregulated in several autoimmune diseases including RA (2). In fact, fibroblasts like synoviocytes (FLS) from RA patients showed a resistance to apoptosis associated with the induction of autophagy (3). Maeshima and colleagues recently demonstrated that tofacitinib suppressed proliferation, but not apoptosis, of CD4+ T cells derived from the synovium (4), but to date there are no data on the effect of inhibition of JAK pathway on autophagy.

Objectives: Since hyperactive autophagy has been associated with impaired apoptosis of RA FLS, the aim of the study was to investigate the role of tofacitinib in modulating autophagy and apoptosis in FLS from RA patients.

Methods: Primary RA FLS isolated from RA biopsies (Figure 1A) were cultured in presence of autophagy inducer rapamycin (as control condition) and tofacitinib $(1 \mu \mathrm{M})$. After $24 \mathrm{~h}$ of culture, autophagy was evaluated both by flow cytometry and 